\title{
Transplantation with Bone Marrow Stromal Cells Promotes Wound Healing Under Chemotherapy through Altering Phenotypes
}

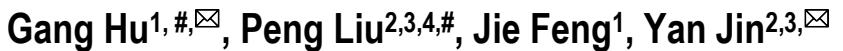

1. Department of Dermatology, Second Hospital of Xi'an Jiaotong University, Xi'an, Shaanxi 710004, China

2. Research and Development Center for Tissue Engineering, Fourth Military Medical University, Xi'an, Shaanxi 710032, China

3. Department of Oral Histology and Pathology, School of Stomatology, Fourth Military Medical University, Xi'an, Shaanxi 710032, China

4. Department of Stomatology, No.201 Military Hospital of PLA, Liaoyang, 111000, China

\# Both authors contributed equally to this work

$\triangle$ Corresponding author: Gang Hu, M.D., Ph.D., Department of Dermatology, Second Hospital of Xi' an Jiaotong University, No.157, West 5th Road, Xi'an, Shaanxi 710004, P. R. China. Tel.: 86-29-8767-9969; Fax: 86-29-8740-9503; E-mail: gang1008@yeah.net. Yan Jin, Ph.D., Prof., Research and Development Center for Tissue Engineering, Fourth Military Medical University, No.145, West Changle Road, Xi'an, Shaanxi 710032, P. R. China. Tel.: 86-29-8477-6147; Fax: 86-29-8321-8039; E-mail: yanjin@fmmu.edu.cn

(C) Ivyspring International Publisher. This is an open-access article distributed under the terms of the Creative Commons License (http://creativecommons.org/ licenses/by-nc-nd/3.0/). Reproduction is permitted for personal, noncommercial use, provided that the article is in whole, unmodified, and properly cited.

Received: 2011.04.14; Accepted: 2011.07.11; Published: 2011.07.31

\begin{abstract}
Stem cell transplantation is a promising strategy for delayed wound healing caused by chemotherapy. However, the fate of stem cells under chemotherapy has not been fully elucidated. Herein we characterized human fetal bone marrow stromal cells (hBMSCs) during wound healing in mice treated with cyclophosphamide (CTX). The isolated hBMSCs expressed the phenotype of CD11b bow/CD14 low $/ C D 34^{\text {low }} / C D 45^{\text {low }} /$ CD29high /CD44high/CD90high/CD105 high/CD146high/STRO-1 1 low. Following in vitro exposure to CTX, hBMSCs showed decreased cell growth in a dose- and time-dependent manner, accompanied by increased expressions of collagen-I/III, and CD31. After transplantation, wounds closed as early as 8 days and were positive for a-smooth muscle actin (a-SMA), implicating the enhanced re-epithelialization and wound contraction. Moreover, proliferating cell nuclear antigen (PCNA) and CD31 showed co-localization with a-SMA, suggesting the differentiation of hBMSCs into epithelial cells and myofibroblasts/fibroblasts. Taken together, our results indicate hBMSCs can accelerate wound healing under chemotherapy through altering their phenotypes.
\end{abstract}

Key words: bone marrow stromal cells; delayed wound healing; cyclophosphamide; cell function

\section{Introduction}

Cyclophosphamide (CTX) is a common drug widely used in chemotherapy. It functions by slowing or blocking cell growth and compromising the immune system's response. However, a lot of side effects have evolved (1). One is delayed or impaired wound healing, which frequently occurs in the patients undergoing surgery due to long-term chemotherapy (1). Treatment for this condition remains difficult and largely ineffective, because the growth of cells in the wound is inhibited (2) and chemotherapy usually leads to myelosuppression, the latter of which further compromises the migration of multipotent cells from the bone marrow (3).

Nevertheless, myelosuppression can be reversed by autologous stem cell transplantation (SCT), even without additional toxicity $(4,5)$. So does allogeneic 
SCT $(6,7)$. Increasing studies indicate SCT provides a promising strategy for the treatment of problematic wounds. However, the fate of stem cells under chemotherapy has not been fully elucidated.

In order to eliminate the interference from the transplanted cells themselves, fetal stem cells were used for transplantation because the proliferation and differentiation potentials of fetal stem cells are superior to the adult ones (8). Moreover, the state of stem cells is a prerequisite and basis for their application. Previous studies reported that old patients had high risks in chemotherapy (9) and the wound healing was compromised with the increase of age (10). These may be attributed to the changes in the functional status of stem cells. Therefore, fetal stem cells are suitable cells for clarifying the influences of CTX on cell functions.

Herein, the growth and proliferation, gene expression, multipotency and phenotype of cultured hBMSCs were compared with those incubated with CTX. Then, hBMSCs were transplanted into the full-thickness skin wound in the severe combined immune deficiency (SCID) mice conditioned with high-dose CTX and wound healing was assessed by cell proliferation and dermal regeneration.

\section{Materials and Methods}

\section{Cell culture and characterization}

This study was approved by the Ethical Committee of Fourth Military Medical University and the informed consent was obtained from each parent before study. Bone marrow was collected from the anterior superior iliac spine of two 7-month-old human fetuses from induced abortion and nucleated cells were isolated using Percoll $(1.073 \mathrm{~g} / \mathrm{ml}$; GE Healthcare, UK) density gradient centrifugation. Nucleated cells were seeded in T25 dishes at a density of $1 \times 10^{5}$ cells $/ \mathrm{cm}^{2}$ and maintained in MesenPRO RSTM medium (Gibco, USA) at $37^{\circ} \mathrm{C}$ in a humidified atmosphere with $5 \% \mathrm{CO}_{2}$. The medium was refreshed every 3 days. When cell confluence reached $80 \%$, cells were harvested and passaged. Cells from passage 3 to 5 were used for the following experiments.

Flow cytometry: aliquots containing $10^{5} \mathrm{hBMSCs}$ were incubated at $4^{\circ} \mathrm{C}$ for $1 \mathrm{~h}$ with $100 \mu \mathrm{l}$ of FITC-conjugated mouse anti-human $\mathrm{mAb}$ to CD11b, CD14, CD29, CD34, CD45, or CD90 (eBioscience, USA), STRO-1, rabbit anti-human pAb CD105 and isotype-matched control, independently. The cells treated with rabbit anti-human CD105 mAb were incubated with FITC-conjugated goat-anti-rabbit IgG (Santa Cruz, USA). After washing twice and re-suspension, quantitative fluorescence analysis was performed using a FACS Calibur cytometer (Beck-
man-Coulter, USA). Aliquots containing $10^{6}$ hBMSCs were analyzed for cell cycle after 1 week of culture.

The hBMSCs of passage 3 were seeded in a 12 -well plate at a density of $1 \times 10^{4}$ cells $/ \mathrm{cm}^{2}$. When the cell confluence reached $80 \%$, the medium was replaced with osteogenic (a-MEM, 7\% fetal calf serum [FCS], $0.1 \mu \mathrm{M}$ dexamethasone, $10 \mu \mathrm{mM}$ $\beta$-glycerolphosphate and $50 \mathrm{mg} / \mathrm{L}$ ascorbate-2-phosphate) or adipogenic induction medium (a-MEM, 7\% FCS, $0.25 \mu \mathrm{M}$ dexamethasone, $100 \mu \mathrm{M}$ indomethacin, $0.5 \mathrm{mM} 3$-isobutyl methylxanthine and $10 \mathrm{mg} / \mathrm{L}$ insulin). The media were refreshed every 3 days. After 2 weeks, cells were stained with Alizarin Red S and Oil-red O (Sigma, USA) to detect the mineralized nodules and neutral lipid vacuoles.

Cell proliferation assay: hBMSCs were seeded in a 96-well plate at a density of 1200 cells/well, and cell proliferation was determined by using methyltetrazolium (MTT) assay after 1-9 days of culture.

\section{Real-time $P C R$}

Total RNA were extracted from the cultured hBMSCs using RNeasy extraction kit (Invitrogen, USA) and first-strand cDNA synthesis was performed according to the manufacturer's instructions (TaKaRa, Japan). Primers were as follows: $\beta$-actin: TGGCACCCAGCACAATGAA (forward), CTAAGT CATAGTCCGCCTAGAAGCA (reverse); Type I collagen (Col-I): CCCGGGTTTCAGAGACAACTTC (forward), TCCACATGCTTTATTCCAGCAATC (reverse); Type III collagen (Col-III): CCACGGAAACACTGGTGGAC (forward), GCACATCAAGGACATCTTCAGGA (reverse); CD31: AGGCCCTCAAGGTTTCCAAGG (forward), CCAGACCATTGTGTCCCCTAA (reverse); KRT14 (CK14): AACTGCTCGCTCGCTCACCT (forward), AGGAGCCCTTCATGGAGCTG (reverse); KRT17 (CK17): GCTGGAGGTGAAGATCCGTGA (forward), ATTGTCCACGGTGGCTGTGA (reverse); KRT19 (CK19): CTGAGTGACATGCGAAGCCAATA (forward), CAGTAACCTCGGACCTGCTCATC (reverse).

Real-time PCR was performed with an iQ5 Real-Time PCR Detection System (Bio-Rad Laboratory, USA) by using SYBR ${ }^{\circledR}$ Green PCR Master Mix (Applied Biosystems, USA) according to the manufacturer's instructions. The thermocycling parameters were optimized as follows: pre-denaturation at $95^{\circ} \mathrm{C}$ for 30 sec, 40 cycles of denaturation at $95^{\circ} \mathrm{C}$ for $10 \mathrm{sec}$, annealing at $60^{\circ} \mathrm{C}$ for $20 \mathrm{sec}$, extension at $95^{\circ} \mathrm{C}$ for $1 \mathrm{~min}$ and a final extension at $60^{\circ} \mathrm{C}$ for $1 \mathrm{~min}$. PCR products were quantified with the Bio-Rad iQ5 Optical System Software and the mRNA expressions of target genes were normalized by that of $\beta$-actin. 


\section{Characterization of CTX treated hBMSCS}

The hBMSCs of passage 3 were seeded in 6-well plates at a density of $1 \times 10^{4}$ cells $/ \mathrm{cm}^{2}$. After culture overnight, CTX was added into the media at the final concentration of $20 \mathrm{mg} / \mathrm{L}$ (low-dose) or $200 \mathrm{mg} / \mathrm{L}$ (high-dose). Then, the cell proliferation, phenotype, cell cycle, multipotency, and gene expressions were analyzed.

\section{Wound preparation and transplantation}

Twenty-five SCID mice were divided into 5 groups: control group, CTX group, CTX+Col-I group, CTX+Col-I+hBMSCs group and CTX+hBMSCs group. SCID mice in the latter 4 groups were injected with high-dose CTX subcutaneously at $24 \mathrm{~h}$ before transplantation. Mice were anesthetized intraperitoneally with $1 \%$ sodium pentobarbital, and skin was prepared. Then, a $1.5-\mathrm{cm}^{2}$ full-thickness wound including the panniculus carnosus muscle was made on the mid back. In the CTX+Col-I+hBMSCs group, $10^{6} \mathrm{hBMSCs}$ were labeled with fluorescent dye PKH-26 and mixed with type I collagen (Sigma, USA). Then the cell suspension was transplanted into the wound bed followed by wound closure. In the CTX+hBMSCs group, $10^{6}$ PKH-26 labeled hBMSCs were re-suspended in $300 \mu 1$ of normal saline, which were injected into the wound bed and marginal area. Finally, the wounds were covered with transparent semiocclusive dressings (Tegaderm, 3M, USA) in all groups.

\section{Wound observation}

Wound healing was observed at the postoperative day 8 and 16. All wounds were healed and scars were observed on day 21. Mice were euthanized and the entire wounds including the normal skin $2 \mathrm{~mm}$ away from the wound margin were excised and fixed in cold acetone and 10\% formalin for the following experiments.

\section{Immunohistochemistry}

Tissues were cut into 5- $\mu \mathrm{m}$ sections. After deparaffinization and hydration, antigen retrieval was performed and endogenous peroxidase was inactivated with $3 \% \mathrm{H}_{2} \mathrm{O}_{2}$. Sections were blocked with normal goat serum for $30 \mathrm{~min}$ and then treated with mouse-anti-human $\mathrm{mAb}$ proliferating cell nuclear antigen (PCNA), CK14, CK17, CK19 and Col-I, rabbit-anti-human pAb CD31, a-smooth muscle actin (a-SMA), or matrix metalloproteinases-1 (MMP-1) (Abcam, UK) at $37^{\circ} \mathrm{C}$ for $1 \mathrm{~h}$. After treatment with secondary antibody, these sections were visualized using DAB kit (EnVision ${ }^{\mathrm{TM}}$ Detection system, DAKO, Denmark), followed by counterstaining with hematoxylin and observation under a light microscope.
Primary antibodies were replaced with PBS serving as negative controls.

\section{Immunofluorescence double staining}

Cryosections ( $8 \mu \mathrm{m}$ in thickness) were fixed with cool acetone and blocked with serum. For double staining, the primary antibodies were rabbit anti-human CD31 and anti-human a-SMA pAbs, the second antibodies used were mouse anti-human PCNA, CK14 and CK17 mAbs, and TRITC-conjugated goat-anti-rabbit IgG and FITC-conjugated goat-antimouse IgG were used as fluorescent antibodies. After incubation with primary antibodies overnight at $4^{\circ} \mathrm{C}$, TRITC-conjugated antibody was added followed by incubation at $37^{\circ} \mathrm{C}$ for $1 \mathrm{~h}$, and then FITC-conjugated antibody was added followed by incubation at $37^{\circ} \mathrm{C}$ for $1 \mathrm{~h}$. Finally, Hoechst33342 was used for counterstaining. Sections were visualized using a fluorescent microscope (Olympus, Japan). Images were acquired with the DP Manager software, and processed with Adobe Photoshop.

\section{Statistical analysis}

Statistical analysis was performed with SPSS version 13.0 statistic software package. Comparisons between two groups were done by using the independent samples $t$ test. A value of $\mathrm{P}<0.05$ was considered statistically significant.

\section{Results}

\section{Decreased growth and proliferation of hBMSCs after CTX treatment}

After 7 days, there was no obvious morphological alterations and cell death after low and high dose CTX treatment (Fig. 1a). Some adherent cells showed elongated morphology, transparent cell body and favorable light refraction when compared with control group (Fig. 1b). hBMSCs incubated with CTX showed decreased growth from day 1 to day 7. On day 9, hBMSCs growth was significantly inhibited in the high-dose CTX group ( $\mathrm{P}<0.05)$ (Fig. 1c). Cell cycle analysis revealed the proportion of cells in the G2/S phase was $13.2 \%$ under normal condition, $5.6 \%$ after low-dose CTX treatment and $4 \%$ after high-dose CTX treatment. In particular, the percentage of cells in S phase was remained at the same level $(4.8 \%$ and $4.7 \%)$ in the former two groups and 2.2 in the latter one (Fig. $1 d)$. These results indicate the growth and proliferation of stem cells is suppressed due to the cytotoxicity of chemotherapy which is a dose and time dependent manner, but the DNA synthesis is only inhibited by high-dose CTX treatment. Therefore, high-dose CTX was used for further study. 

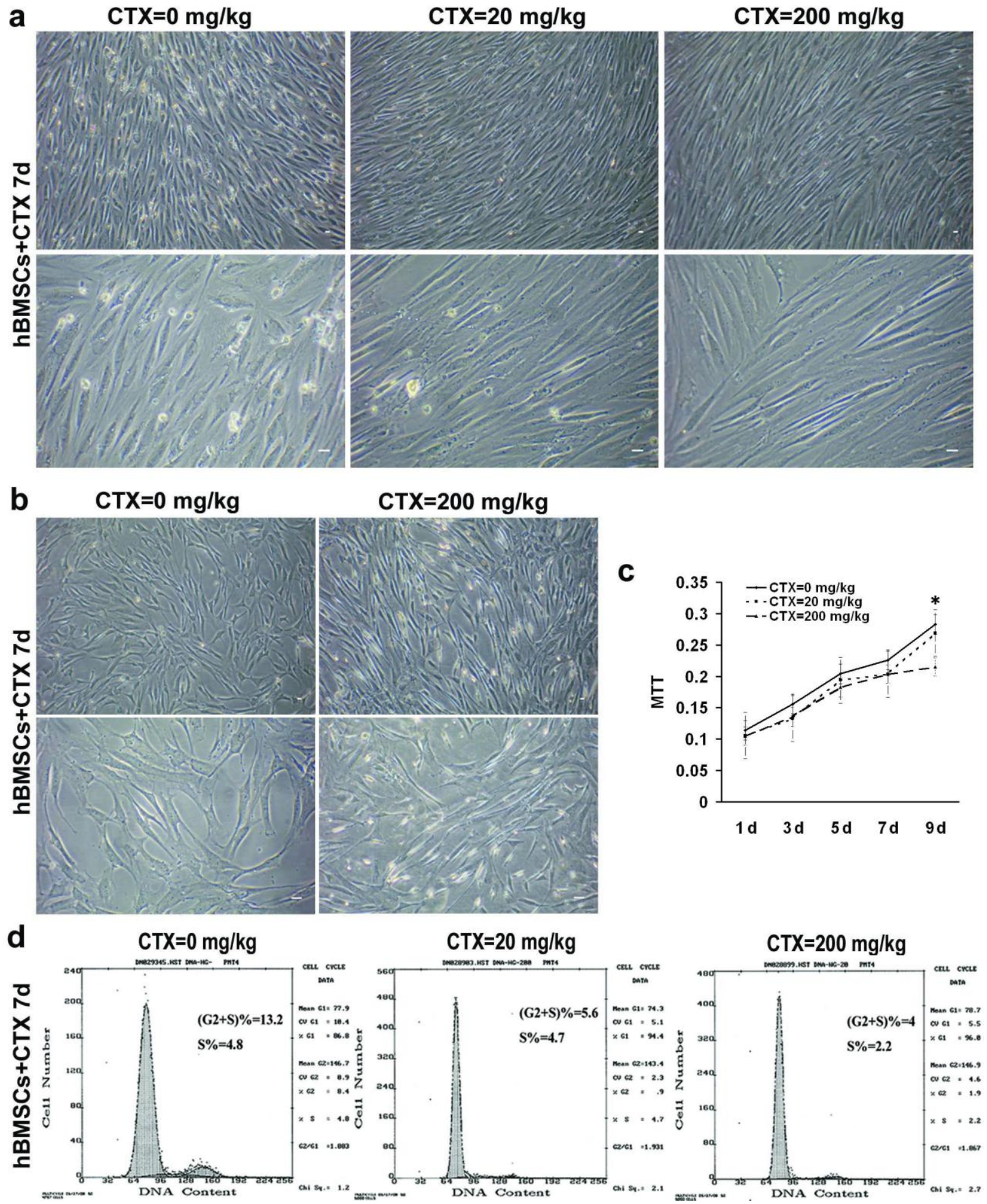

Fig. 1. Decreased growth and proliferation of hBMSCs after CTX treatment. (a) There was no obvious morphological alterations and cell death 7 days after low and high dose CTX treatment. (b) Some adherent cells showed elongated appearance, and transparent cell body and had light refraction. (c) hBMSCs treated with CTX of different doses showed decreased growth from day 1 to day 7. Until 9 days after high-dose CTX treatment, hBMSCs showed significantly decreased growth when compared with control group ( ${ }^{*} \mathrm{P}<0.05$ vs 20 and $200 \mathrm{mg} / \mathrm{kg}$ groups). (d) Cell cycle analysis revealed the proportion of cells in G2/S phase was $13.2 \%$ under normal condition, $5.6 \%$ after low-dose CTX treatment and $4 \%$ after high-dose CTX treatment. In particular, the proportion of cells in S phase was remained at the same level $(4.8 \%$ and $4.7 \%)$ in the former two groups and $2.2 \%$ in the latter one. Bar $=50 \mu \mathrm{m}$. $\mathrm{d}=\mathrm{day}(\mathrm{s})$. 


\section{Alterations in phenotype, and multipotency after CTX incubation}

The expressions of cell markers between cells in the control group and those incubated with high-dose CTX are shown in Fig. 2. Results showed the significantly decreased expressions of hematopoietic markers CD11b (from $5.4 \%$ to $1.3 \%$ ), CD14 (from $6.3 \%$ to $1.5 \%$ ), CD34 (from $5.7 \%$ to $1.5 \%$ ) and CD45 (from $6.8 \%$ to $1.4 \%$ ) in the high-dose CTX group. The expressions of mesenchymal markers CD29 (from 100\% to 99.9\%), CD105 (from 100\% to $97.1 \%$ ), CD90 (from 100\% to $100 \%$ ) remained stable, but that of STRO-1 increased (from 5.2\% to $7.4 \%$ ). Of note, there was significantly decreased expression of endothelial/mesenchymal marker CD146 (from 75\% to 32.3\%). These findings indicate the growth and proliferation of progenitors derived from hematopoietic lineage are suppressed, but those from mesenchymal lineage are not significantly influenced, except for cells expressing CD146 which is also concerned as an endothelial cell marker. We speculate that hematopoietic and endothelial characteristics are inhibited, which is different from the maintenance of mesenchymal features under this condition.

After induction, mineralized nodules and neutral lipid vacuoles were found. After incubation with CTX, there was a significant increase of cell death, especially after adipogenic treatment. After two weeks of treatment, Alizarin Red S and Oil red-O staining showed obvious osteogenesis but impaired adipogenesis, which may be attributed to the increase of CTX dose (Fig. 2b).

\section{hBMSCs accelerate the healing of wounds condi- tioned with CTX}

On day 8 and 16, wound healing was significantly accelerated in the CTX+Col-I group, the CTX+Col-I+hBMSCs group and the CTX+hBMSCs group when compared with control group, but delayed wound healing was revealed in the CTX group (Fig. 3a). In particular, the wound beds in the CTX + Col-I group were ulcerative and exudative, while those in the CTX+Col-I+hBMSCs group and the CTX+hBMSCs group showed increase of re-epithelialization, in which the wounds were almost closed on day 8 . These findings indicate Col-I treatment or/and hBMSCs transplantation can improve the healing of wounds conditioned with CTX.

On day 21, H\&E staining revealed complete re-epithelialization in the healed samples of all groups. Two significant differences were observed.
The number of vessel-like structures in the wound bed was the most in the control group and the least in CTX+Col-I group. The density of dermal layer was the highest in CTX+Col-I+hBMSCs group and the lowest in CTX group (Fig. 3b-f). These findings suggest impaired angiogenesis or vascular recession at that moment in the CTX+Col-I group, and enhanced collagen production and/or proliferation of fibroblasts after transplantation in the CTX+Col-I+hBMSCs group.

\section{hBMSCs proliferate in the regenerated skin and MMP- 1 contributes to collagen degradation}

Positive staining of PCNA was observed in not only the wound bed, but also the margin of the healed tissues in the CTX+Col-I+hBMSCs group. Positive staining was mainly found in the superficial papillary layer and deep reticular layer of dermis (Fig. 4a-c).

However, positive staining of Col-I was not found in the wound bed (Fig. 4d), and weak staining of Col-I observed in the interfollicular area and deep reticular layer of dermis in the margin of healed tissues in the CTX+Col-I+hBMSCs group (Fig. 4e, f). Similarly, negative staining of Col-I was observed in the wound bed (Fig. 4g) and positive staining of Col-I noted in both papillary and reticular layers of dermis in the margin of healed tissues in the CTX+hBMSCs group (Fig. 4h, i). These results indicate type I collagen treatment inhibits the collagen production by hBMSCs, and the animals receiving injection of hBMSCs alone have more collagen production, demonstrated by strong staining of Col-I in the margin.

Real-time PCR analysis revealed the expressions of Col-I and Col-III were slightly decreased on day 7 but increased on day 14 in hBMSCs incubated with high dose CTX. The expressions of both genes were significantly increased by 13.8 and 8.2 folds when compared with that on day 0 (Fig. 4j). These results indicate the collagen production is enhanced after CTX treatment.

Nevertheless, the results from PCNA staining were inconsistent with those from Col-I staining. In order to explain this discrepancy, MMP-1 staining was performed. Results showed the wound bed was strong positive for MMP-1, suggesting tissue remodeling in CTX+Col-I+hBMSCs group and CTX+hBMSCs group. Therefore, weak staining of Col-I was probably due to collagen degradation (Fig. $4 \mathrm{k}, 1)$. 
a
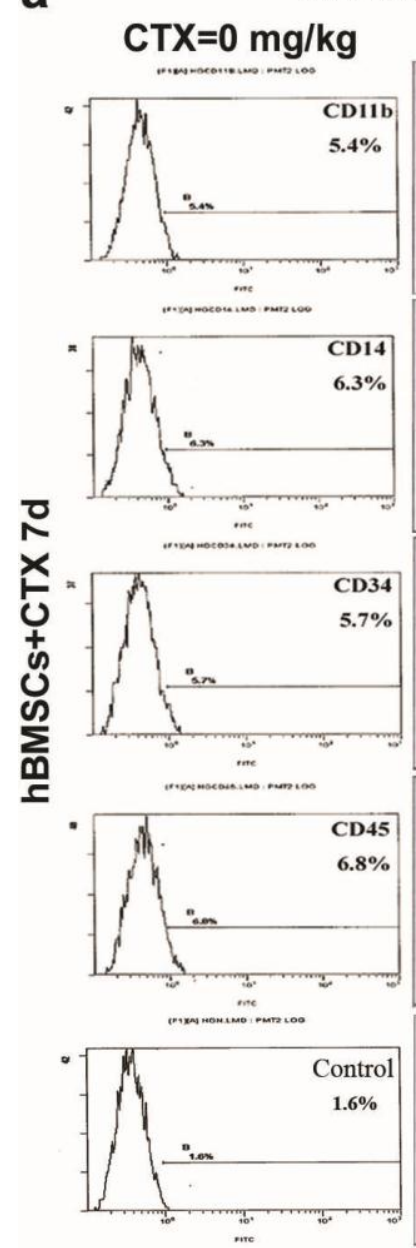

b
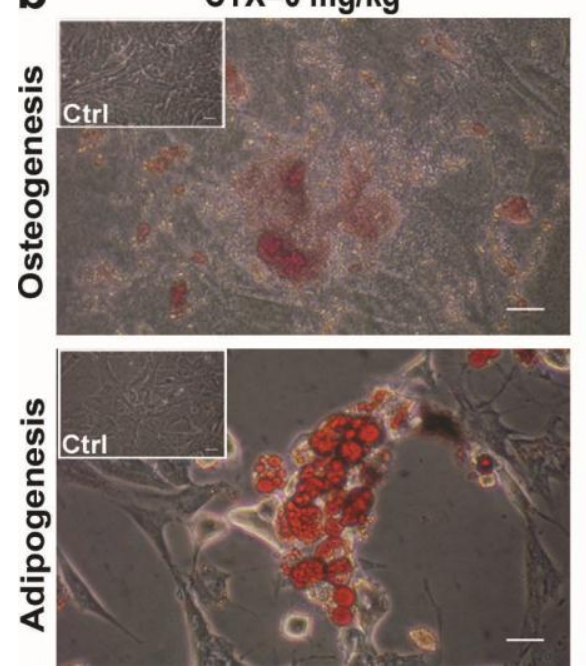

\section{CTX $=200 \mathrm{mg} / \mathrm{kg}$}
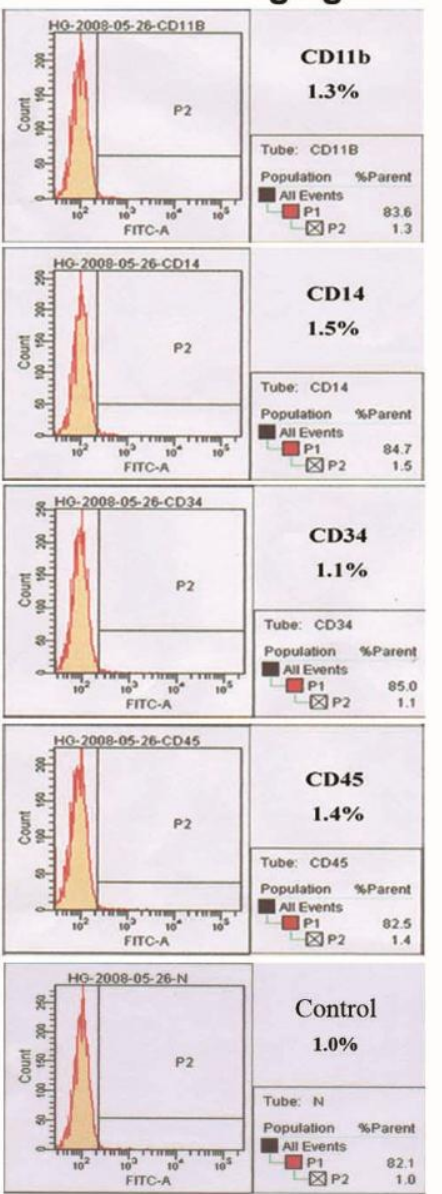

Mesenchymal

\section{CTX $=0 \mathrm{mg} / \mathrm{kg}$}
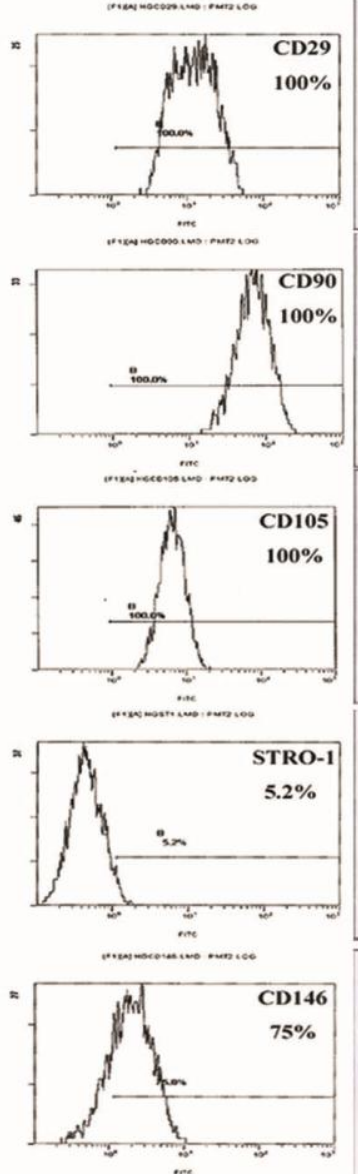

\section{CTX=200 mg/kg}
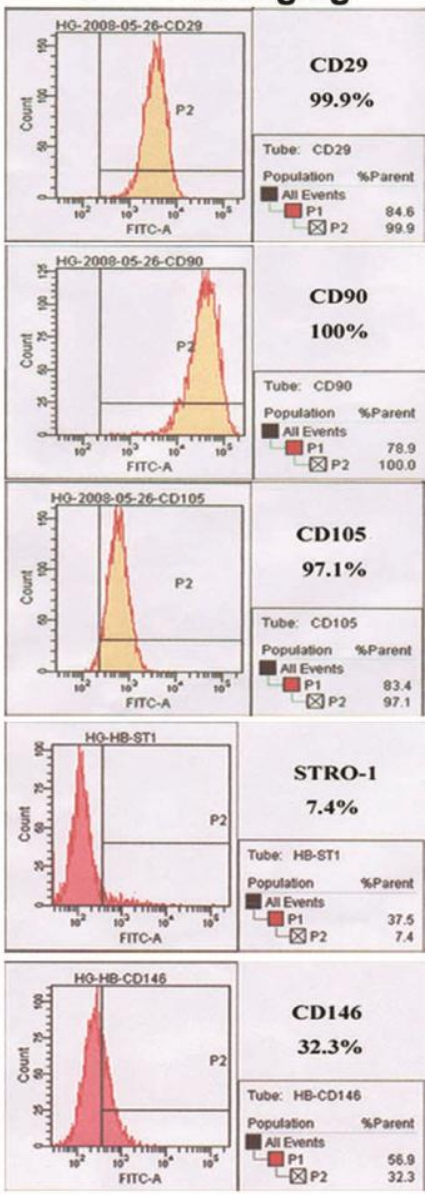

CTX=200 mg/kg
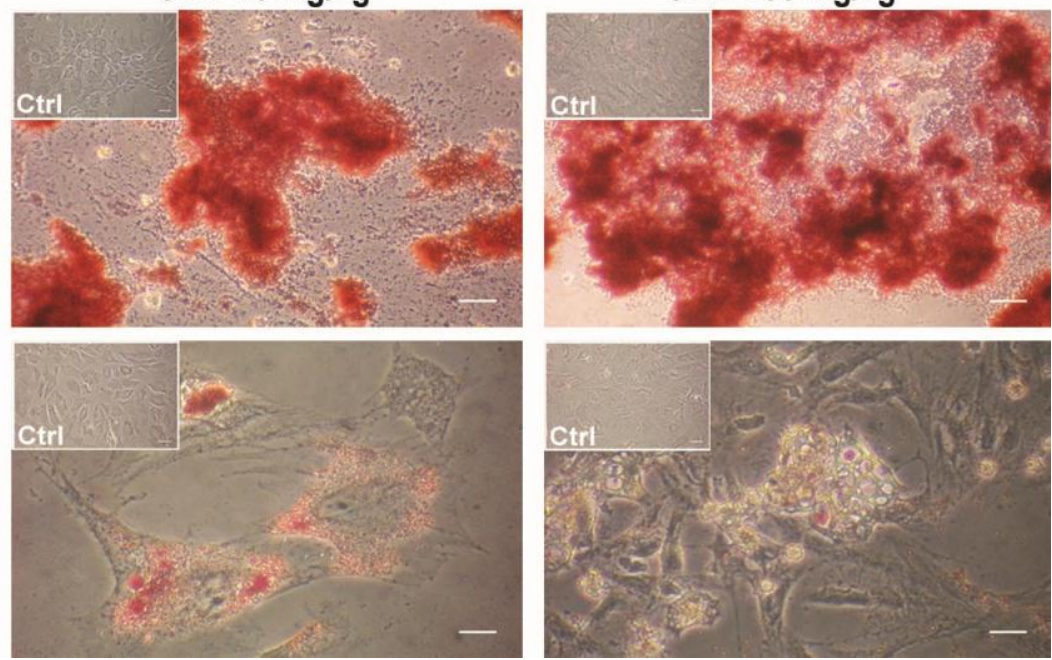

Fig. 2. Phenotype, and multipotency after CTX treatment. (a) Decreased expressions of hematopoietic markers CD11b, CD14, CD34 and CD45. Expressions of mesenchymal markers CD29, CD105, CD90 were remained stable but that of STRO-1 increased. Of note, the expression of endothelial/mesenchymal marker CD146 was significantly decreased. (b) After CTX treatment, there was a significant increase in cell death, especially in adipogenic groups. After 2 weeks of CTX, Alizarin Red $\mathrm{S}$ and Oil red-O staining showed active osteogenesis and impaired adipogenesis which was related to the increase of CTX dose. Bar=50 $\mu \mathrm{m}$. d=day(s). 

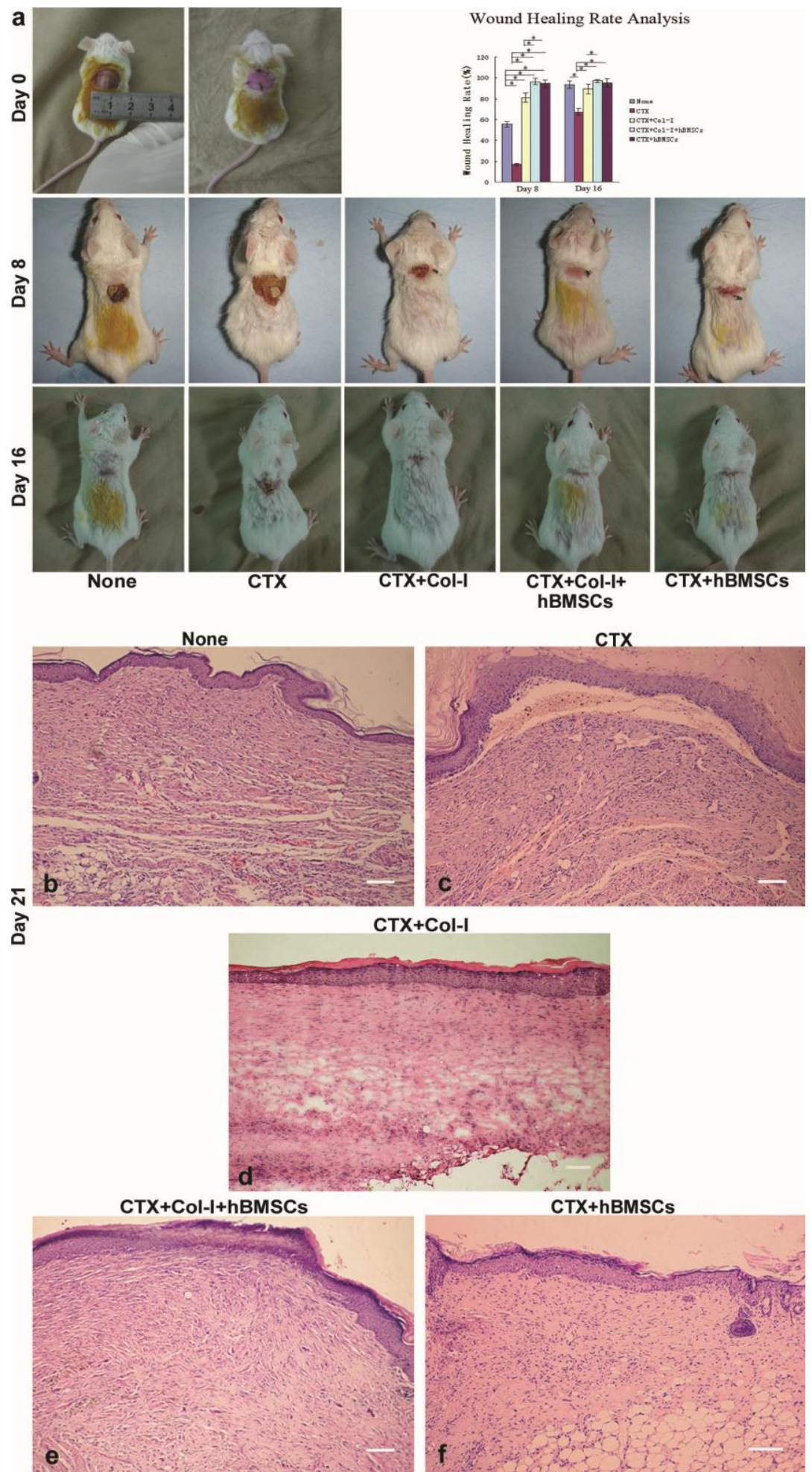

Fig. 3. hBMSCs accelerated the healing of wounds conditioned with CTX. (a) On day 8 and day 16, wound healing was significantly accelerated in $\mathrm{CTX}+\mathrm{Col}-\mathrm{I}$ group, $\mathrm{CTX}+\mathrm{Col}-\mathrm{I}+\mathrm{hBMSCs}$ group and $\mathrm{CTX}+\mathrm{hBMSC}$ sroup when compared with control group, and delayed healing was revealed in CTX group. Wound beds in CTX+Col-I group were ulcerative and exudative, while those in CTX+Col-I+hBMSCs group showed evident re-epithelialization. The wounds were almost closed on day 8 . The wound healing rate in the CTX+Col-I+hBMSCs was markedly higher than that in CTX group. (b-f) On day 21, H\&E staining revealed complete re-epithelialization in the healed tissues of all groups. The number of vessel-like structures in the wound bed was the most in control group and the least in CTX+Col-I group. Additionally, the density of dermal layer was the highest in $\mathrm{CTX}+\mathrm{Col}-\mathrm{I}+\mathrm{hBMSC}$ group and the lowest in CTX group. Bar $=100 \mu \mathrm{m}$. 
PCNA

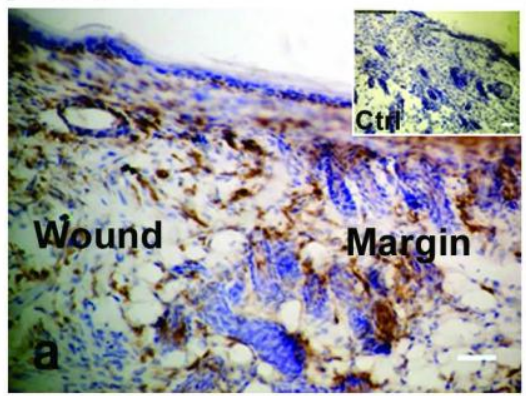

Col-I

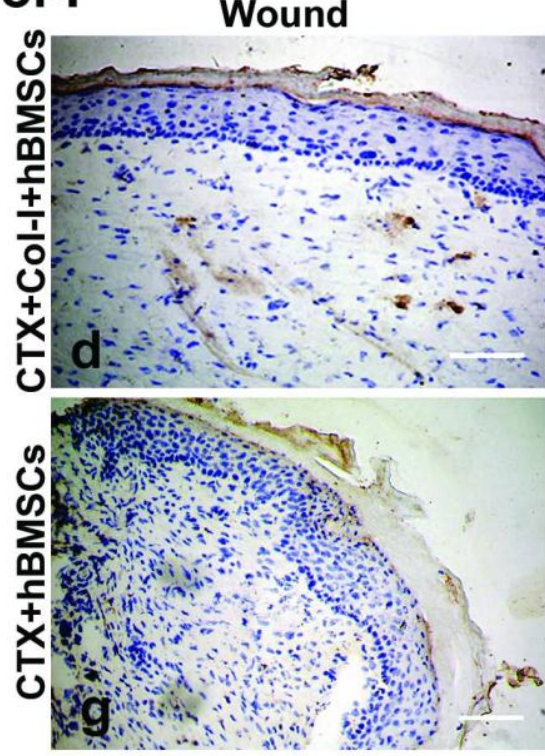

CTX+Col-I+hBMSCs

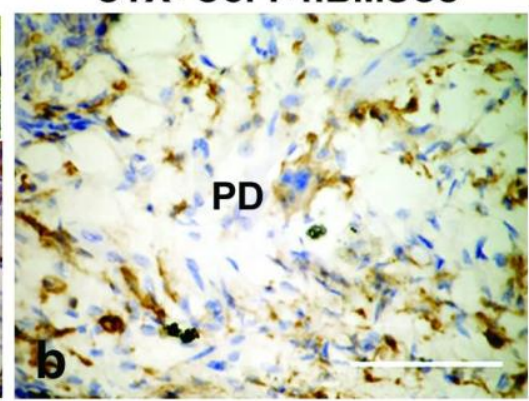

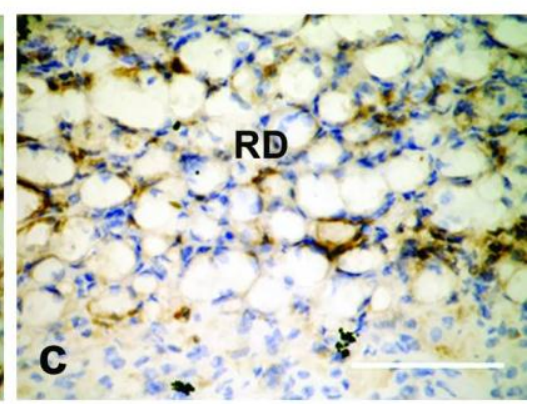

Margin

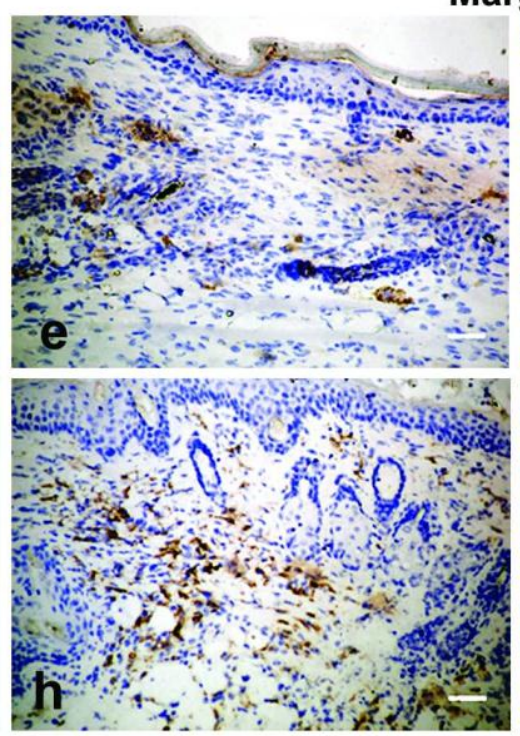

j

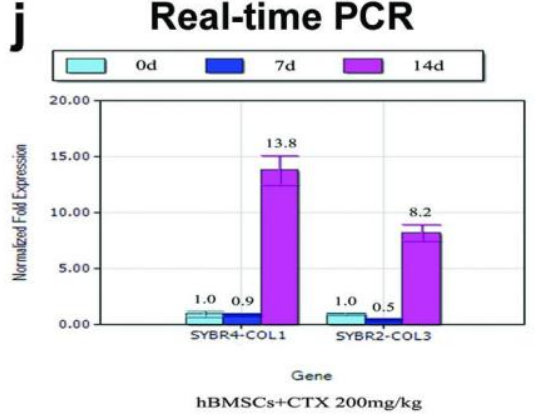

MMP-1

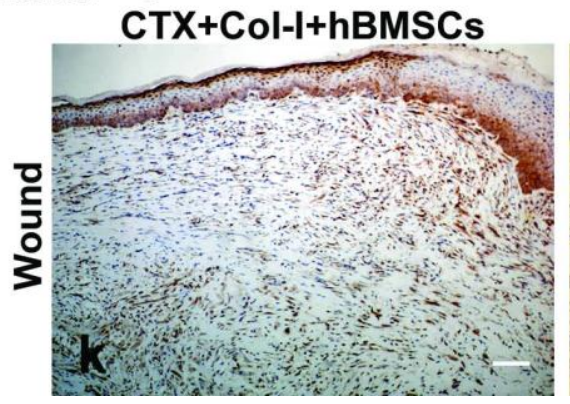

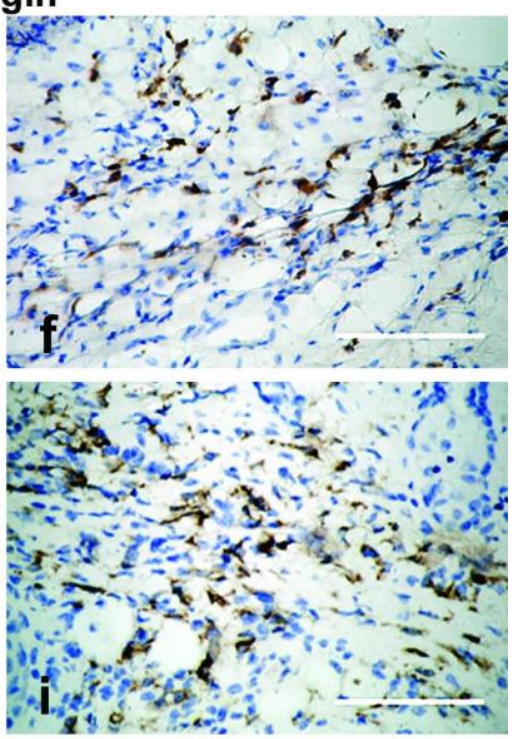

Fig. 4. hBMSCs proliferated in regenerated skin and MMP-1 contributed to collagen degradation. (a-c) Positive staining of PCNA was observed in not only the wound bed, but also the margin of the healed tissues of CTX+Col-I+hBMSCs group. Positive staining was mainly found in the papillary and reticular dermis. (d-f) Negative staining of Col-I was observed in the wound bed, but weak staining noted in the interfollicular area and reticular dermis in the margin of healed tissue in CTX+Col-I+hBMSCs group. (g-i) Negative staining of Col-I was observed in the wound bed, but positive staining in the papillary and reticular dermis in the margin of healed tissues in CTX+hBMSCs group. (j) Real-time PCR analysis revealed the expressions of Col-I and Col-III were slightly decreased on day 7 and the rapidly increased on day 14. (k, l) The wound bed of healed tissues was strong positive for MMP-1 in both groups. Bar $=100 \mu \mathrm{m} . \mathrm{PD}=$ papillary dermis. RD=reticular dermis.

Differentiated hBMSCs expressing CD31 were in not only vessel-like structures, but also dermis

Notably, only vessel-like structures were positive for CD31, a marker of endothelial cells, in the
CTX group (Fig. 5a, i), and both vessel-like structures and stromal cells were positive for CD31 in the CTX+Col-I+hBMSCs group (Fig. 5b, ii, iii). Moreover, CD31 was also noted in the dermis of the margin of 
healed wounds in the CTX+Col-I+hBMSCs group (Fig. 5c). Real-time PCR analysis revealed the expression of CD31 was decreased at early stage but increased at later stage in hBMSCs incubated with high dose CTX (Figure 5d). Double immunostaining showed CD31 and PCNA were co-locolized in some parts of dermis in CTX+Col-I+hBMSCs group (Fig. $5 e)$. These results indicate hBMSCs participate in the dermal regeneration and some of them are derived from endothelial lineage.

\section{CD31}
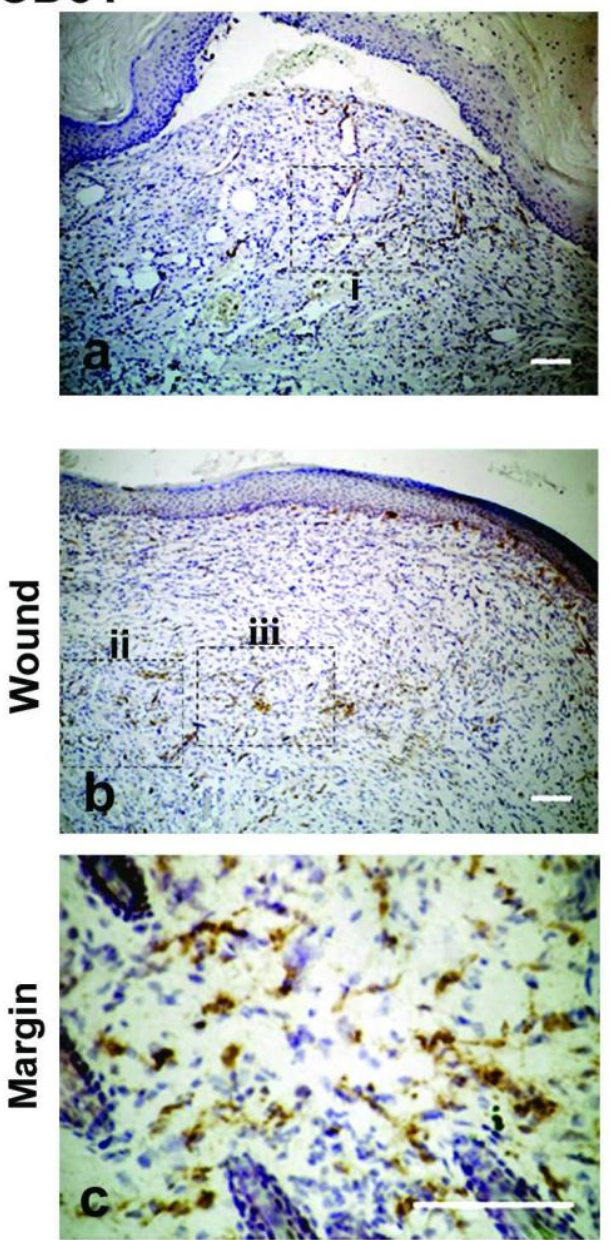

\section{CTX}

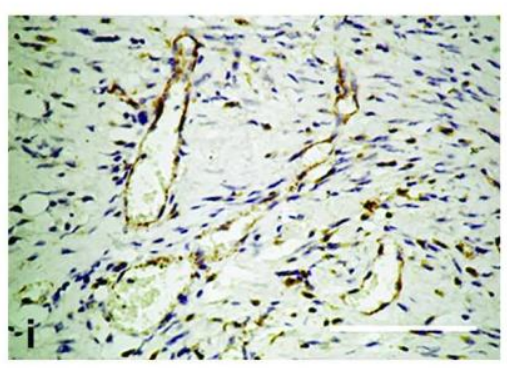

\section{CTX+Col-I+hBMSCs}

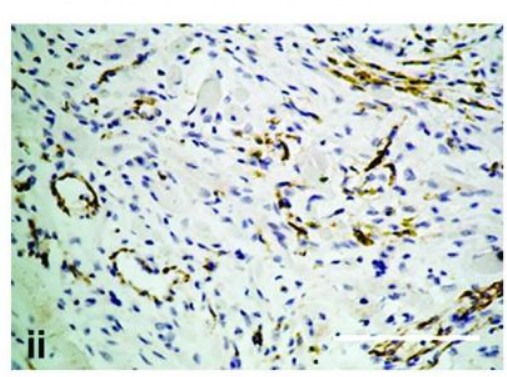

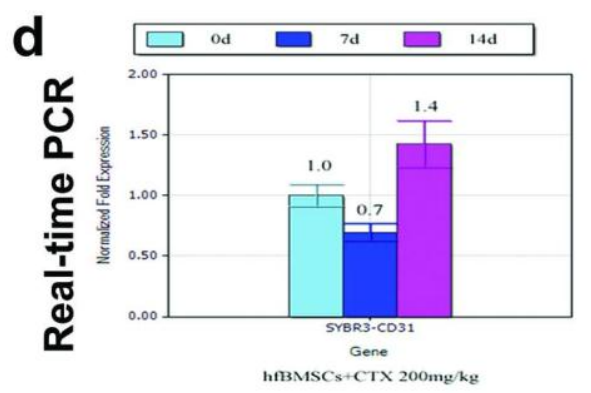

e CD31 PCNA Hoech
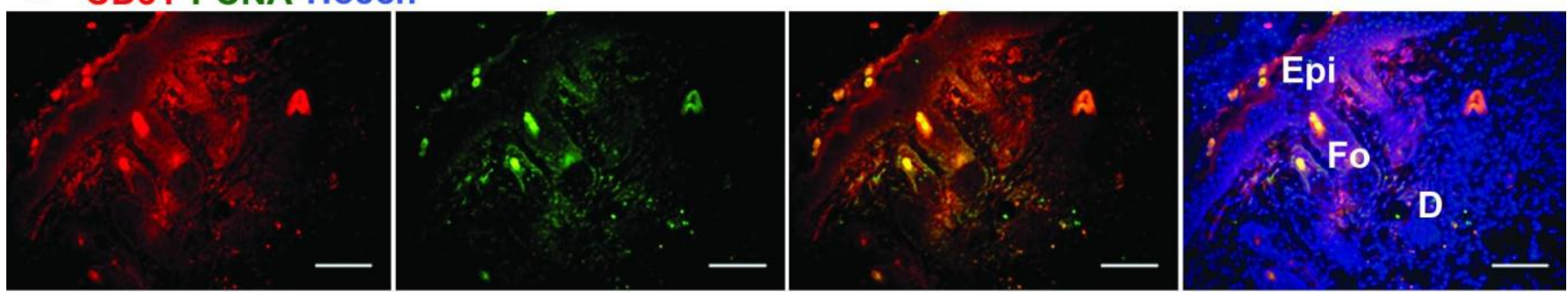

Fig. 5. Differentiated hBMSCs express CD31 in both vessel-like structures and dermis. (a,b) only vessel-like structures was positive for CD31 in CTX groups, and both vessel-like structures and stromal cells positive for CD31 in CTX+Col-I+hBMSCs group. (c) The dermis of the margin of healed wounds was positive for CD31 in CTX+Col-I+hBMSCs group. (d) Real-time PCR analysis revealed the CD31 expression was decreased at early stage followed by an increase at late stage. (e) Double immunostaining showed CD31 and PCNA were colocolized in some parts of the dermis. 

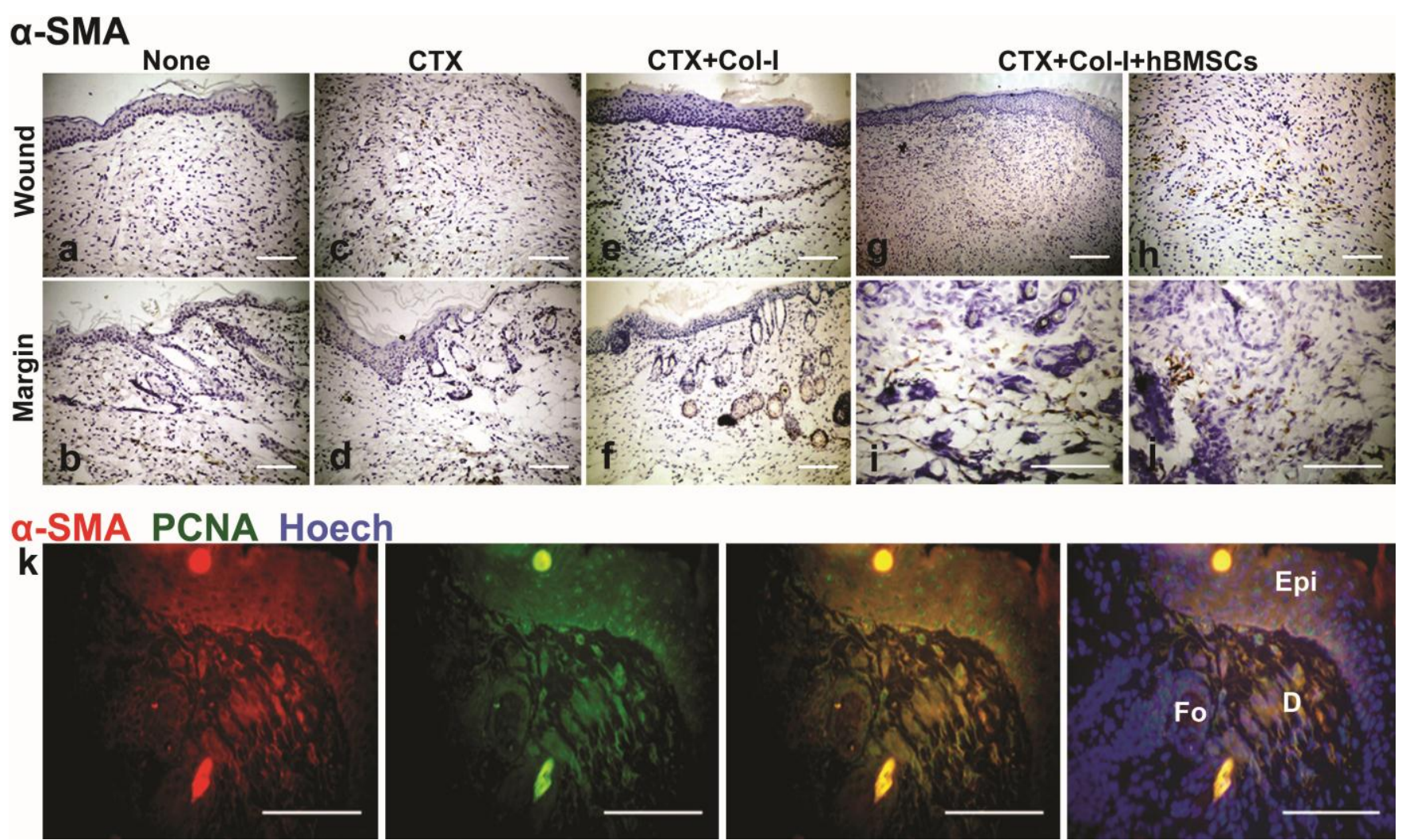

Fig. 6. hBMSCs differentiated into myofibroblasts. (c,g-j) a weak and uncertain staining of a-SMA was found in the wound bed of CTX group and positive staining in not only the wound bed but also the margin of healed tissues of CTX+Col-I+hfBMSCs group. $(a, b, e, f)$ both wound bed and margin of healed tissues were negative for $a-S M A$ in control group and CTX+Col-I group. (d) The wound margin of healed tissues was positive for a-SMA in CTX group. (k) Double immunostaining revealed a-SMA and PCNA were colocolized in dermal stroma.

\section{hBMSCs differentiate into myofibroblasts}

Immunostaining of a-SMA showed a weak and uncertain staining in the wound bed in the CTX group (Fig. 6c) and positive staining in not only the wound bed but the margin of healed wounds in the CTX+Col-I+hBMSCs group (Fig. 6g-j). However, the wound bed and margin of healed tissues were negative for a-SMA in the control group and the CTX+Col-I group (Fig. 6a, b, e, f), even in the margin of healed wounds in the CTX group (Fig. 6d). a-SMA is a marker of myofibroblasts and PCNA is a marker of cell proliferation. Double immunostaining revealed a-SMA and PCNA were co-locolized in the dermal stroma (Fig. 6k). These results indicate transplanted hBMSCs can differentiate into myofibroblasts which also proliferate in the wound.

\section{hBMSCs incubated with CTX express CK14/17/19 and proliferate in epidermis, hair follicles with simultaneous expression of CD31}

On day 7 and 14, real-time PCR showed a tendency of decreasing first and increasing later in gene expression of CK14, a continuously increased tendency in gene expression of CK17/19 when set the incubation time of $0 \mathrm{~d}$ as control, the increased rate of gene expression was as labeled (Fig. 7a). Strong Staining of PCNA in wound margin concentrated on the epidermis, hair follicles and sebaceous glands; CD31 was also stained positive in the marginal region of CTX+Col-I+hBMSCs group, including epidermis and hair follicles compared with that of PCNA (Fig. $7 \mathrm{~b})$. By double immunostaining, CD31 and PCNA were overlapped in some parts of epidermis, hair follicles and dermis (Fig. 7c).

\section{hBMSCs differentiate into epithelial Cells with simultaneous expression of CD31}

Positive staining of CK14 was found in basal cell compartments of stratified and combined epithelia in the regenerated epidermis and hair follicles (Fig. $8 a, b)$. Positive staining of CK19 was found in the basal layer of the squamous epithelia and ductal and glandular epithelia of hair follicles (Fig. 8e,f). Positive staining of CK17 was found in some parts of internal 
and surrounding area of hair follicles and minor basal cell epithelia (Fig. 8c,d). By double immunostaining, CD31 and CK14 overlapped in some parts of epidermis and hair follicles, and CD31 and CK17 overlapped in some parts of internal and surrounding area of hair follicles and minor basal cell epithelia (Fig. 8b).

\section{hBMSCs differentiate into myofibroblasts and ep- ithelial cells}

Positive staining of a-SMA was found in the wound margin in CTX+Col-I+hBMSCs group. Posi- tive staining of a-SMA was found in the minor basal cell compartments, glandular-like area of the epidermis and hair follicles other than stroma (Fig. 9a). Positive staining of MMP-1 was found in sebaceous glands, hair follicles and epidermis in CTX+Col-I group and CTX+Col-I+hfBMSCs group (Fig. 9b). By double immunostaining, a-SMA and PCNA overlapped in dermal stroma, epidermis and hair follicles (Fig. 9c). $\mathbf{a}$

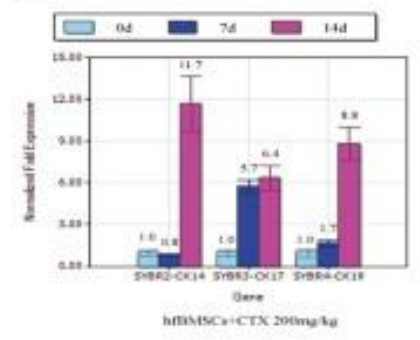

b
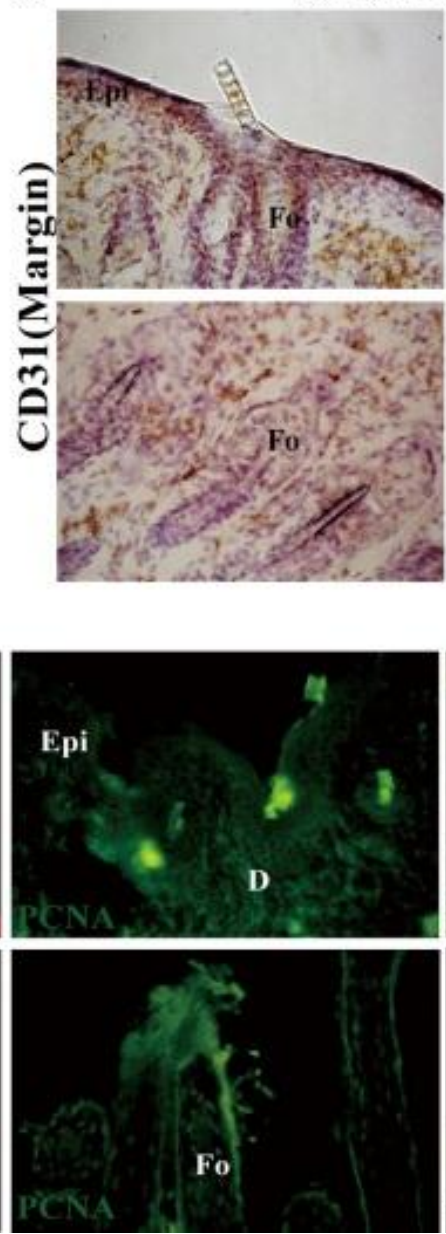
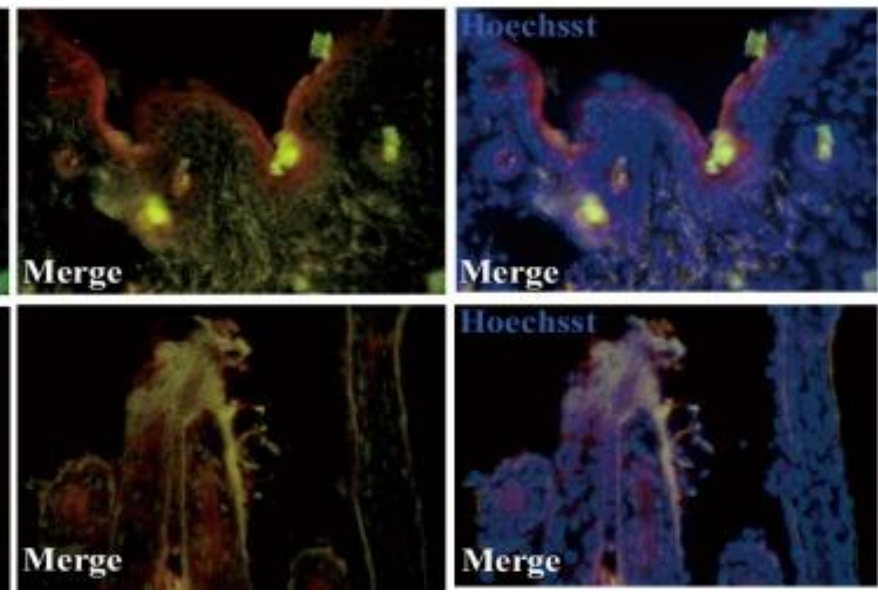
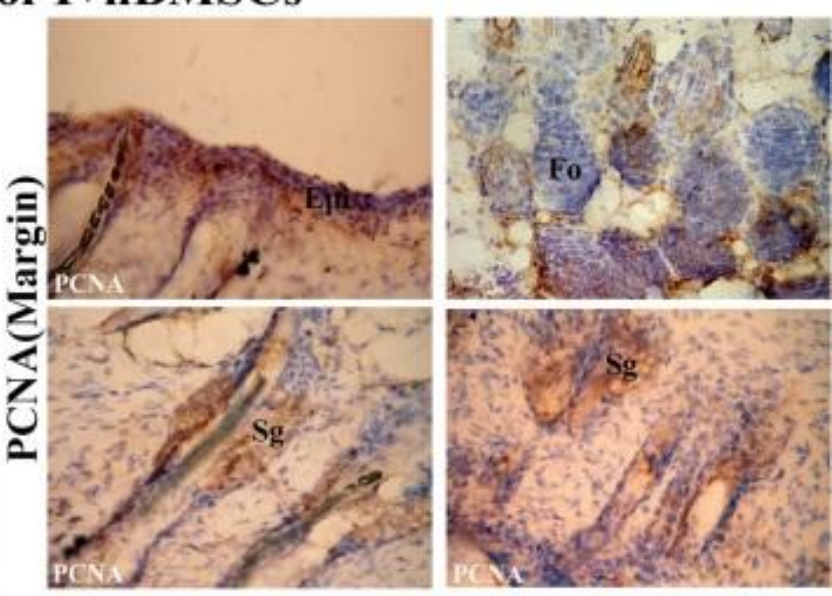

Fig. 7. hBMSCs differentiate into epithelial cells. (a) On day 7 and 14, real-time PCR showed a tendency of decreasing first and increasing later in gene expression of CK14, a continuously increased tendency in gene expression of CK17/19 when set the incubation time of $0 \mathrm{~d}$ as control, the increased rate of gene expression was as labeled. (b) Strong Staining of PCNA in wound margin concentrated on the epidermis, hair follicles and sebaceous glands; CD31 was also stained positive in the marginal region of CTX+Col-I+hBMSCs group, including epidermis and hair follicles compared with that of PCNA. (c) By double immunostaining, CD31 and PCNA were overlapped in some parts of epidermis, hair follicles and dermis. Epi=epidermis. $\mathrm{D}=$ dermis. Fo=hair follicle. $\mathrm{Sg}=$ sebaceous gland. 

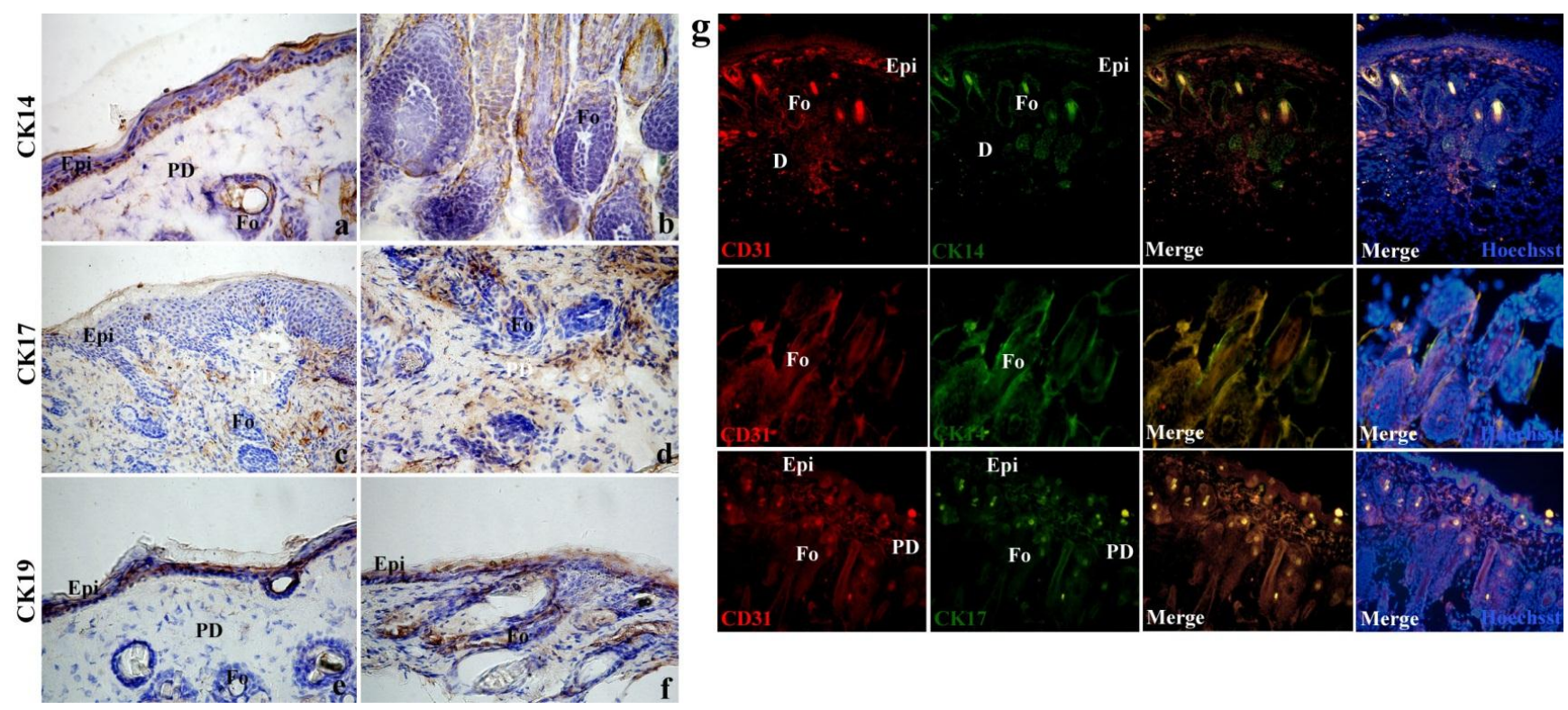

Fig. 8. hBMSCs differentiate into epithelial cells. (a,b) Positive staining of CK14 in basal cell compartments of stratified and combined epithelia in the regenerated epidermis and hair follicles. (e,f) Positive staining of CK19 in the basal layer of the squamous epithelia and ductal and glandular epithelia of hair follicles. (c,d) Positive staining of CK17 in some parts of internal and surrounding area of hair follicles and minor basal cell epithelia. (g) By double immunostaining, CD31 and CK14 overlapped in some parts of epidermis and hair follicles, CD31 and CK17 overlapped in some parts of internal and surrounding area of hair follicles and minor basal cell epithelia. Epi=epidermis. $\mathrm{D}=$ dermis. PD=papillary layer of dermis. $\mathrm{RD}=$ reticular layer of dermis. Fo=hair follicle.

\section{Discussion}

The optimal healing of a cutaneous wound requires a well-orchestrated integration of the complex biological and molecular events including cell migration and proliferation, extracellular matrix deposition, angiogenesis, and remodeling (11). However, these processes are possibly altered under chemotherapy, which may cause delayed or impaired wound healing.

The detrimental effects of chemotherapy are dose-dependent and time-relevant. There were no significant differences in the growth and proliferation among cells treated with CTX of different doses from day 1 to day 7 , but marked differences were observed on day 9 between low dose CTX group and high-dose CTX group. In vivo transplantation of hBMSCs consistently demonstrated the accelerated wound healing, and the wounds were almost completely closed on day 8. Therefore, it seemed that CTX was not harmful to the transplanted hBMSCs within 7 days.

Isolated hBMSCs contain mixed populations of hematopoietic and mesenchymal cells. The expressions of hematopoietic markers CD11b, CD14, CD34 and CD45 were decreased after CTX treatment, which was consistent with previous reports that hematotoxicity represented a major side effect on stem cells (12). The decreased expression of hematopoietic markers possibly implied the growth inhibition of macrophages/monocytes $\left(\mathrm{CD}_{11 b^{+}} / \mathrm{CD} 14^{\text {+low }} / \mathrm{CD} 34^{+} /\right.$ $\left.\mathrm{CD}^{4} 5^{+}\right)$, which compromises the infiltration of macrophages/monocytes into the wound. Macrophages/monocytes are pivotal to the wound healing, functioning not only as director cells, but as phagocytes in addition to producing chemoattractants and growth factors which are necessary for the repair and control of wound healing $(13,14)$. We speculate that the decreased infiltration is a two-edged sword. On one side, reduced macrophages/monocytes alleviate the graft-versus-host disease $(15,16)$. On the other, reduced chemoattractants and growth factors limit the migration of endothelial cells and/or endothelial progenitor cells, which compromise the angiogenesis. Therefore, few vessel-like structures were formed in the healed tissue of CTX group, even in the CTX+hBMSCs group.

a-SMA is a marker of myofibroblasts. In the present study, co-locolization of a-SMA and PCNA was found after hBMSC transplantation suggesting the transplanted hBMSCs can differentiate into myofibroblasts which also proliferate in the wound. However, the expression of CD31 is not markedly increased after CTX treatment and the expression of CD146, another marker of endothelial cells, is reduced by almost $50 \%$. These results indicate the differentiation of hBMSCs into endothelial cells is suppressed by 
CTX treatment but these cells can differentiate into myofibroblasts. Moreover, immunohistochemistry and fluorescence staining demonstrate the presence of a-SMA positive cells in the newly generated skins suggesting the differentiation of hBMSCs into myofibroblasts. The myofibroblasts are the main effector cells during the wound healing and the components of newly generated skins.
The results from multipotency induction showed impaired adipogenesis but active osteogenesis. This was similar to previous reports in which adipogenic differentiation was blocked by the immunosuppressant $(17,18)$ and the survival of mesenchymal progenitor cells in the bone marrow during chemotherapy allowed for osteogenic regeneration (19).
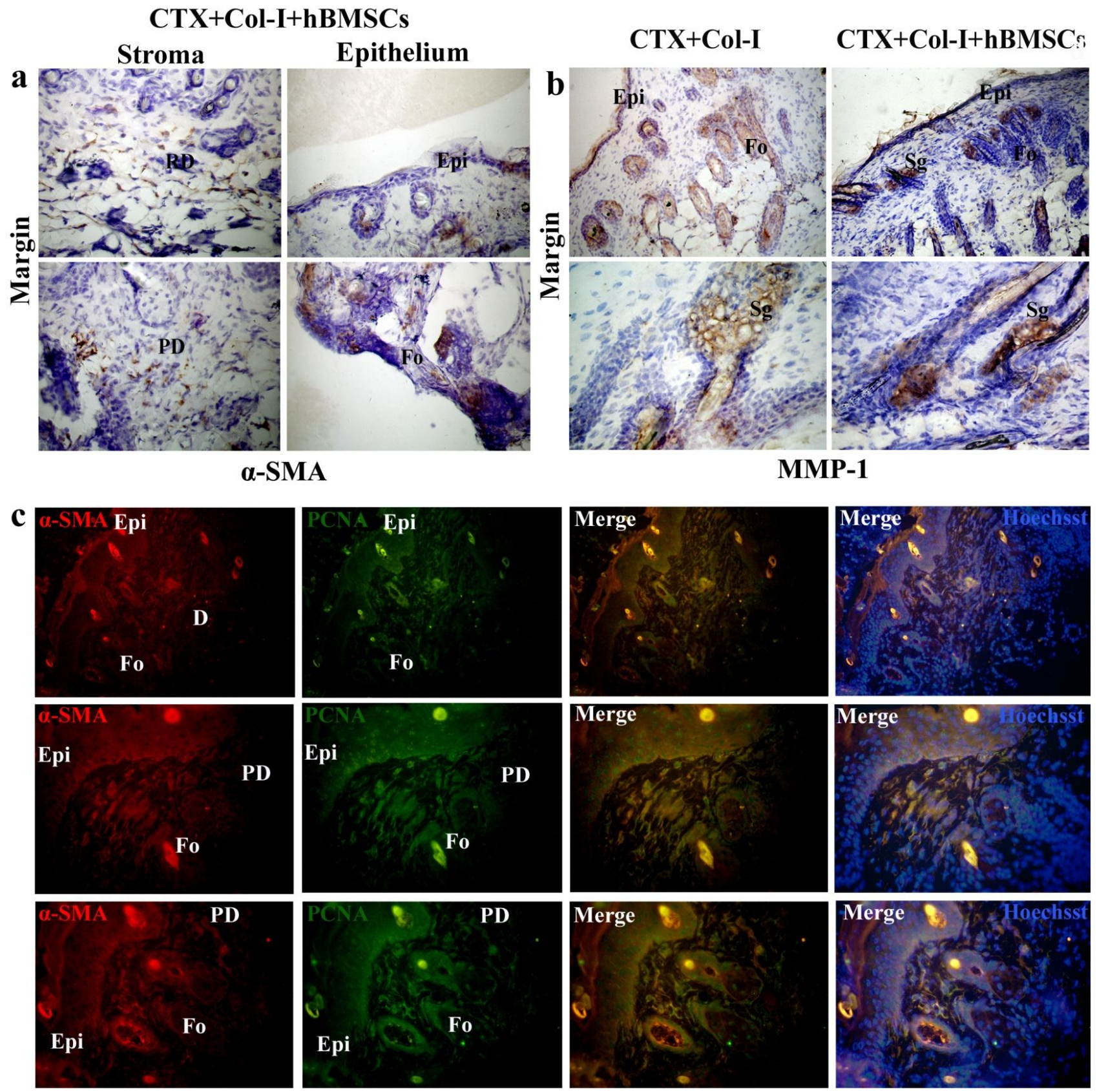

Fig. 9. hBMSCs differentiate into myofibroblasts and epithelial cells. (a) Positive staining in the wound margin in CTX+Col-I+hBMSCs group. Positive staining of a-SMA in the minor basal cell compartments, glandular-like area of the epidermis and hair follicles other than stroma. (b) Positive staining of MMP-1 in sebaceous glands, hair follicles and epidermis in CTX+Col-I group and CTX+Col-I+hfBMSCs group. (c) By double immunostaining, a-SMA and PCNA overlapped in dermal stroma, epidermis and hair follicles. Epi=epidermis. $\mathrm{D}=$ dermis. $\mathrm{PD}=$ papillary layer of dermis. RD=reticular layer of dermis. Fo=hair follicle. 
The expressions of Col-I and Col-III were significantly increased after CTX treatment, especially the Col-I expression was increased more than 13 folds. This was consistent with the study of Fathke et al (20) in which bone marrow-derived cells were found to transcribe both collagen types I and III, whereas the skin-resident cells transcribed only collagen type I. It has been reported that delayed administration of CTX until 7 days after surgery may produce minimal impairment (21) to the wound healing, and the reduced collagen production by dermal fibroblasts is due to the adverse effects of irradiation and chemotherapy (2). These results indicate the importance of increased collagen production by hBMSCs to the acceleration of wound healing. Moreover, our study showed increased expression of MMP-1 indicating collagen degradation and, as a result, the Col-I content in the healed tissues was reduced in CTX+Col-I+hBMSCs group and CTX+hBMSCs group. Consistently, MMPs play an important role in the remodeling of extracellular matrix. They are lowly expressed in normal adult tissues, but highly expressed under pathological conditions, such as wound healing and cancer invasion $(22,23)$.

Regenerated epithelial cells and myofibroblasts/fibroblasts expressing endothelial marker CD31 are probably differentiated through the mechanism similar to a partial endothelial-to-mesenchymal transition (EMT). EMT is initially delineated for the cardiovascular development and recently noticed in the various pathologic settings, including pathophysiological vascular remodeling, invasion of malignancy and fibrosis. We noticed endothelial marker CD31 was colocalized with PCNA in the epidermis, hair follicles and dermis. Simultaneously, regenerated epithelial cells were also positive for CK14/17/19, which has correlation with CD31. This was important to the healing as we observed the re-epithelialization enhancement at the $8^{\text {th }}$ day post-transplantation. Consistently, in vitro gene expression assays showed the significantly increased expressions of CK14/17/19 after incubation with CTX. Taken together, hBMSCs have the potential of differentiation into epithelial cells, and the regenerated cells simultaneously expressing CKs and CD31 verify the differentiation process through EMT. Moreover, MMP-1 was found in the epidermis, hair follicles and sebaceous glands of wound margin, which supports the disruption of intercellular contacts and cell release from the parent epithelial tissues. We also observed the positive staining of a-SMA in regenerated myofibroblasts/fibroblasts. This is consistent with the notion that EMT-derived cells are believed to function as fibroblasts in damaged tissue, and may therefore have an important role in tissue remodeling and fibrosis. These perhaps represent the essential features of EMT that the resulting mesenchymal-like phenotype is suitable for migration.

Differentiated myofibroblasts contribute to wound contraction and positive staining of a-SMA in the regenerated epidermis and hair follicles indicates a reverse epithelial-to-mesenchymal transition. We only found clearly positive staining of a-SMA in the wound bed and margin of the healing tissues in the CTX+Col-I+hBMSCs group, however this phenomenon was not seen in control groups. This result is not consistent with that of Fathke et al. in which EGFP+ bone marrow cells did not immunostain with muscle cell markers suggesting these cells were not differentiating into myofibroblasts although they did appear to have a contractile phenotype when placed in vitro. We postulate that EMT is not the regular mechanism occurring during wound healing in normal condition other than those delayed or impaired wound healing. Notably, positive staining of a-SMA was observed in some parts of epidermis and hair follicles in the wound margin, which were colocalized with PCNA. These findings provide preliminary evidence of epithelial differentiation from hBMSCs, possibly through a reverse epithelial-to-mesenchymal transition (or mesenchymal-to-epithelial transition).Together with the expression of MMP-1, the regenerated epithelial cells contribute to re-epithelialization through cell migration. Similar phenomenon was also reported in corneal wound.

There are still limitations in this study. We did not compare the biological features of hBMSCs after low-dose and high-dose CTX treatment and the histological analysis was not done after transplantation of hBMSCs undergoing treatment of CTX at different concentrations. In addition, the specific mechanism of the promoted wound healing after hBMSC transplantation is still unclear and should be further investigated in future studies.

Taken together, our results show short-term high-dose CTX treatment does not significantly affect the proliferation of hBMSCs and these cells have significant increase of expressions of Col-I and Col-III after this treatment. Moreover, after transplantation of high-dose CTX treated hBMSCs, the wound healing is significantly promoted, especially at 8 days after transplantation.

\section{Acknowledgements}

This work was supported by the Development of High and New Science and Technology ('863' Project) of China (No. 2006AA02A119) and the Fundamental Research Funds for the Central Universities. 


\section{Conflict of Interests}

All authors declare they have no conflicts of interest.

\section{References}

1. Guillot B, Bessis D, Dereure O. Mucocutaneous side effects of antineoplastic chemotherapy. Expert Opin Drug Saf. 2004; 3(6): 579-87.

2. Springfield DS. Surgical wound healing. Cancer Treat Res. 1993; 67: 81-98.

3. Shigeoka Y, Shimizu E. Myelosuppression due to antineoplastic agents. Nippon Rinsho. 2007; 65 (Suppl 8): 287-93.

4. Hawkins DS, Felgenhauer J, Park J, et al. Peripheral blood stem cell support reduces the toxicity of intensive chemotherapy for children and adolescents with metastatic sarcomas. Cancer. 2002; 95(6): 1354-65.

5. Laurence V, Pierga JY, Barthier S, et al. Long-term follow up of high-dose chemotherapy with autologous stem cell rescue in adults with Ewing tumor. Am J Clin Oncol. 2005; 28(3): 301-9.

6. Feinstein L, Sandmaier B, Maloney D, et al. Nonmyeloablative hematopoietic cell transplantation. Replacing high-dose cytotoxic therapy by the graft-versus-tumor effect. Ann N Y Acad Sci. 2001; 938: 328-37.

7. Khouri IF, Saliba RM, Giralt SA, et al. Nonablative allogeneic hematopoietic transplantation as adoptive immunotherapy for indolent lymphoma: low incidence of toxicity, acute graft-versus-host disease, and treatment-related mortality. Blood. 2001; 98(13): 3595-9.

8. O'Donoghue K, Fisk NM. Fetal stem cells. Best Pract Res Clin Obstet Gynaecol. 2004; 18(6): 853-75.

9. Repetto L. Greater risks of chemotherapy toxicity in elderly patients with cancer. J Support Oncol. 2003; 1(4 Suppl 2): 18-24.

10. Arnesen SM, Lawson MA. Age-related changes in focal adhesions lead to altered cell behavior in tendon fibroblasts. Mech Ageing Dev. 2006; 127(9):726-32.

11. Chodorowska G, Roguś-Skorupska D. Cutaneous wound healing. Ann Univ Mariae Curie Sklodowska Med. 2004;59(2):403-7.

12. Lapidot T. Mechanism of human stem cell migration and repopulation of NOD/SCID and B2mnull NOD/SCID mice. The role of SDF-1/CXCR4 interactions.Ann N Y Acad Sci. 2001 Jun;938:83-95.

13. Martin P, Leibovich SJ. Inflammatory cells during wound repair: the good, the bad and the ugly. Trends Cell Biol. 2005; 15(11): 599-607.

14. Tsirogianni AK, Moutsopoulos NM, Moutsopoulos HM. Wound healing: immunological aspects. Injury. 2006; 37 (Suppl 1): S5-12.

15. Teshima T, Ferrara JL. Understanding the alloresponse: new approaches to graft-versus-host disease prevention. Semin Hematol. 2002; 39(1): 15-22.

16. Sun Y, Tawara I, Toubai T, et al. Pathophysiology of acute graft-versus-host disease: recent advances. Transl Res. 2007; 150(4): 197-214.

17. Neal JW, Clipstone NA. Calcineurin mediates the calcium-dependent inhibition of adipocyte differentiation in 3T3-L1 cells. J Biol Chem. 2002; 277(51): 49776-81.

18. Kim JE, Chen J. regulation of peroxisome proliferator-activated receptor-gamma activity by mammalian target of rapamycin and amino acids in adipogenesis. Diabetes. 2004; 53(11): 2748-56.

19. Jager M, Schultheis A, Westhoff B, et al. Osteogenic progenitor cell potency after high-dose chemotherapy (COSS-96). Anticancer Res. 2005; 25(2A): 947-54.
20. Fathke C, Wilson L, Hutter J, et al. Contribution of bone marrow-derived cells to skin: collagen deposition and wound repair. Stem Cells. 2004; 22(5): 812-22.

21. Scimeca CL, Bharara M, Fisher TK, et al. Novel use of insulin in continuous-instillation negative pressure wound therapy as "wound chemotherapy". J Diabetes Sci Technol. 2010;4(4):820-4.

22. Ravanti L, Kahari VM. Matrix metalloproteinases in wound repair (review). Int J Mol Med. 2000; 6(4): 391-407.

23. Vihinen P, Kahari VM. Matrix metalloproteinases in cancer: prognostic markers and therapeutic targets. Int J Cancer. 2002; 99(2): 157-6 